\title{
Incentivos fiscales verdes como instrumento de apoyo a la política urbana: un estudio sobre el IPTU VERDE en municipios brasileños
}

\author{
T. C. AZEVEDO* e A. A. PORTELLA \\ Universidade Estadual de Feira de Santana \\ Universidade Federal da Bahia \\ tanaze@terra.com.br*
}

Artigo submetido em 11/09/2018 e aceito em 27/11/2019

DOI: $10.15628 /$ holos.2019.7913

\section{RESUMEN}

El objetivo de esta investigación fue comprobar si los municipios brasileños adoptan incentivos fiscales verdes y si estos contribuyen como instrumento de política urbana. Mediante una revisión bibliográfica, se realizó un reconocimiento de la Tributación ecológica, con énfasis en el IPTU verde como instrumento extra fiscal de política urbana. La metodología utilizada ha sido un estudio descriptivo-explicativo, porque se describen los diferentes incentivos fiscales verdes del IPTU adoptados en Brasil, y explicativa porque pretende comprender los criterios establecidos en las legislaciones locales, y
\end{abstract}

cualitativo en cuanto a su abordaje. Los resultados obtenidos en la investigación sugieren que no hay uniformidad en el modelo aplicado en los municipios de Brasil para los incentivos fiscales verdes del Impuesto sobre la Propiedad Predial y Territorial Urbana (IPTU). Éstos presentan restricciones para actuar como instrumento de política urbana para el desarrollo sostenible, debido sus limitaciones para propiciar los contribuyentes condiciones y medios accesibles para la obtención de este beneficio tributário.

PALABRAS CLAVE: Certificación sostenible, Extrafiscalidad tributaria, Impuesto verde

Green tax incentives as an instrument to support urban policy: a study on the "IPTU VERDE" in Brazilian municipalities

\section{ABSTRACT}

The objective of this research was to verify if the Brazilian municipalities adopt green tax incentives and if they contribute as an instrument of urban policy. Through a bibliographical review, a recognition of Ecological Taxation was made, with emphasis on the Green IPTU as an extra tax instrument of urban politics. The methodology of the study regarding the achievement of the objectives was classified as descriptive-explanatory in nature because it describes the different green tax incentives the IPTU adopted in Brazil and explanatory because it seeks to understand the criteria established in local legislation and qualitative in its approach. The results obtained in the research suggest that there is no uniformity in the model applied in the municipalities of Brazil for the green tax incentives in the field of Property Tax and Urban Territorial Tax (IPTU). These have restrictions to act as an urban policy instrument for sustainable development because of their limitations to provide taxpayers with the conditions and means available to obtain this tax benefit.

KEYWORDS: Sustainable certification, Trubutary extrafiscality, Green tax.

Incentivos fiscais verdes como instrumento de apoio à política urbana: um estudo sobre o IPTU VERDE nos municípios brasileiros

\section{RESUMO}

O objetivo desta pesquisa foi verificar se os municípios brasileiros adotam incentivos fiscais verdes e se contribuem como instrumento de política urbana. Por meio de uma revisão bibliográfica, foi feito um reconhecimento da Tributação Ecológica, com ênfase no IPTU verde como instrumento fiscal extra da política urbana. A metodologia do estudo quanto ao alcance dos objetivos foi classificada como de natureza descritivoexplicativa, porque descreve os diferentes incentivos fiscais IPTU verde adotados no Brasil e explicativa porque procura entender os critérios estabelecidos nas legislações locais e qualitativa na sua abordagem. Os resultados obtidos na investigação sugerem que não há uniformidade no modelo aplicado nos municípios do Brasil para os incentivos fiscais verdes em matéria de Imposto Predial e Territorial Urbano (IPTU). Estes apresentam restrições para atuar como um instrumento de política urbana para o desenvolvimento sustentável, devido às suas limitações para proporcionar aos contribuintes condições e meios acessíveis para obter esse benefício fiscal. 


\section{INTRODUCCIÓN}

El fenómeno de la urbanización intensa ocurrida en las ciudades y la concentración de la actividad económica son factores que, sin duda, se han reflejado en el modelo de crecimiento económico vivido mundialmente, el cual ha dado lugar a una serie de transformaciones en el Planeta Tierra, y ha impuesto presiones sobre el medio ambiente. En Brasil, la expansión poblacional de las ciudades, se reflejó en el bienestar y la calidad de vida de los que habitan en las zonas urbanas. Son retos que los gobernantes y la sociedad en general enfrentan con el fin de perseguir un desarrollo con sostenibilidad.

En ese sentido, el alcalde, por tener conocimiento más cercano de los problemas locales, se convierte en un agente con mayor posibilidad de actuar en favor de prácticas de rehabilitación del medio ambiente. Por lo tanto, podrá actuar en la promoción de objetivos, formulación, ejecución, y mecanismos que incentiven y promuevan el Desarrollo Sostenible (DS). En esta dirección, el Plan director del municipio podrá contemplar la previsibilidad de instrumentos en forma de institutos tributarios, por medio de incentivos o beneficios fiscales ambientales que actúen en favor del DS. Como ejemplo, el Impuesto sobre la Propiedad Predial y Territorial Urbana (IPTU), puede ser utilizado desde una perspectiva ecológica.

Por lo tanto, la tributación ecológica, específicamente los incentivos fiscales verdes en materia de IPTU, tiene por objetivo central indicar que es posible que la inducción tributaria actúe como estímulo, en forma de incentivo al desarrollo sostenible. Esta modalidad ha sido llamada de muchas maneras, por ejemplo: IPTU verde, "ecológico", o "sostenible". En el ámbito académico es posible observar estudios que abordan el asunto, por ejemplo, Rodríguez Muñoz (2004); Passos y Pozzetti (2012); Cunha, Martínez y Nossa (2013); Ventosa, Forn, Sora y Sanz, (2015); Piacentini, Pedro Filho y Almeida (2015), y Azevedo (2017) realizaron investigaciones en esta dirección.

Así, este estudio buscó responder la siguiente pregunta: ¿los incentivos fiscales verdes en materia de IPTU, contribuyen como instrumento de política urbana local? A partir de esto, el objetivo general de este trabajo fue verificar si los municipios brasileños adoptan incentivos fiscales verdes y si estos contribuyen como instrumento de política urbana. Específicamente, a) discutir la adopción de tributación ecológica en el contexto de las prácticas de sostenibilidad ambiental urbana; b) describir las posibilidades de adopción de tributación ecológica en materia de IPTU; c) analizar las legislaciones locales, que versan sobre beneficios tributarios ecológicos en materia de IPTU.

Se trata de un estudio descriptivo-explicativo, cualitativo en cuanto a su abordaje, porque se describen las posibilidades de incentivos fiscales verdes en materia de IPTU adoptados en Brasil, y explicativa, porque objetiva comprender los criterios establecidos en las legislaciones locales. Para eso, se comparó, las regulaciones de los municipios con población superior a 500.000 habitantes.

Los resultados de la investigación apuntan que en cuanto al modelo aplicado en los municipios de Brasil, los incentivos fiscales verdes en materia de IPTU, no hay uniformidad y que estos adoptan variados criterios y modelos. Por esta razón es complejo afirmar que este instituto tributario contribuya de manera práctica como instrumento de política urbana local. 
Ante lo expuesto, la presente investigación se diferencia de otras existentes, básicamente por su recorte espacial, por centrarse en los incentivos fiscales verdes en materia de IPTU de los municipios de Brasil con población superior a 500.000 habitantes.

El presente trabajo se estructura en cinco apartados, considerando la introducción como el primero. En la segunda sección se presentan las bases teóricas relativas a la tributación ecológica y a los incentivos fiscales verdes, en materia de IPTU. La tercera parte expone la metodología utilizada en la construcción del artículo. En el apartado siguiente, se describen los resultados empíricos obtenidos, finalizando con las consideraciones finales.

\section{REVISIÓN DE LA LITERATURA}

\subsection{Tributación ecológica - conceptos, fundamentos y abordajes}

El concepto de tributación ambiental parte del presupuesto de que el tributo representa un instrumento de protección del medio ambiente. Así, se refiere a uno de los mecanismos de que el poder público podrá disponer para hacer efectivo su plan de desarrollo urbano, mediante la utilización de instrumentos tributarios para generar los recursos necesarios para la prestación de servicios públicos de carácter ambiental (aspecto fiscal o recaudatorio), o con el fin de orientar el comportamiento de los contribuyentes hacia la protección del medio ambiente (aspecto extra fiscal o regulatorio), (Ramos, 2006; y Costa, 2011). Y estos deberán estar presentes y ser reconocibles en la estructura de la norma tributaria, a partir del fundamento constitucional, como en las hipótesis del Art. 225 de la Constituicion Federal de Brazil, se entiende que los "tributos ambientales" no son aquellos creados únicamente con fines recaudatorios, (Torres, 2011, p. 16).

En este sentido, los tributos ambientales, que pueden actuar como instrumento de política urbana, eminentemente extra fiscal, son aquellos en los que la base de cálculo es una unidad que tenga repercusión negativa sobre el medio ambiente, de modo que sobre el hecho generador se admitan cinco especies de tributos: impuesto; tasa; contribución de mejora; contribuciones especiales y préstamos forzosos (Ramos, 2006; Gordilho, 2009). Se comprende que la tributación ecológica, ambiental o verde, se trata de una perspectiva que considera el llamado "verdeamiento" de la legislación tributaria como mecanismo de las políticas públicas con vistas al desarrollo sostenible mediante la adopción de impuestos con fines ambientales, subsidios, incentivos y beneficios fiscales (Montero, 2013; Ribeiro y Ferreira, 2011). En consecuencia, se desprende que la tributación podrás ser utilizada como instrumento favorable a la preservación y conservación del medio ambiente (Montero, 2011).

Para Ribeiro y Ferreira (2011, p. 151), la tributación ambiental tiene dos finalidades: la generación de recursos para costear los servicios públicos de naturaleza ambiental, o sea, con fines recaudatorios o fiscales; y otra de naturaleza orientativa, para dirigir el comportamiento de los contribuyentes hacia la preservación del medio ambiente, siendo un incentivo para la adopción de conductas en sintonía con la idea de la preservación ambiental. Esta percepción se ampara en los estudios de Herrera (2000), Buñuel González (2004), Aydos (2010) y Montero (2011) que pusieron en evidencia tales características al considerar dos clasificaciones distintas: a) tributos ambientales lato-sensu (amplio o impropio) - predominantemente recaudatorio, oriundos de la tributación ordinaria, puede haber elementos ambientales que producen un efecto extra fiscal con carácter 
ecológico; y b) tributos ambientales stricto-sensu - TASs (sentido propio) - lo cual vincula la estructura al establecimiento del incentivo de prevención y protección de la naturaleza y del impacto causado al medio ambiente, que tiene finalidad extra fiscal. Son instrumentos que buscan preferiblemente orientar las conductas de los agentes económicos de forma que el impacto medioambiental ocurra de forma sostenible.

Por consiguiente, Buñuel González (2004, p. 42) indica que un tributo ambiental se caracteriza como aquel que debe actuar como incentivo a los agentes económicos para se vean instigados a reducir los efectos nocivos sobre el medio ambiente causados por sus actividades, y así influir en sus comportamientos para satisfacer los objetivos de la política ambiental. Para él, esta visión no incluye solo fines recaudatorios sino también la actuación en el ámbito de la generación de incentivos.

Montero (2013, p. 339) y Peralta (2015, p. 4) ratifican que la tributación ambiental se clasifica en cuanto a su naturaleza como de finalidad extra fiscal, la finalidad primordial no es el carácter fiscal o recaudatorio, sino su objetivo organizador, buscando inducir o desestimular cierto tipo de conducta de los contribuyentes, en la medida en que sean o no anheladas por la sociedad. Para ellos, esta tributación deberá actuar sobre los incentivos a los agentes económicos para que estos se vean obligados a reducir los efectos nocivos que sus actividades causan al medio ambiente. Entienden que hay distintas denominaciones tales como tributos ecológicos, verdes o "ecotaxes" que se caracterizan por ser instrumentos económicos que adopta el estado como medio de protección del medio ambiente.

En el escenario internacional se observa el estudio de Thalmann (2004), que investigó los factores determinantes de los resultados de un referéndum celebrado en 2000 en Suiza, en que 4,7 millones de ciudadanos suizos fueron invitados por el gobierno a votar tres propuestas de impuestos sobre energía fósil. Ello también intentó verificar lo que esto enseña sobre la aceptación pública de los impuestos verdes. Para responder a estas cuestiones, Thalmann (2004) relacionó las características de los ciudadanos a sus votos, teniendo en cuenta al mismo tiempo la elección de la participación. Sus hallazgos apuntaron que ciudadanos con afinidad por partidos verdes y de centroizquierda ( $17 \%$ de la muestra) y ciudadanos con educación superior (32\%) tuvieron tasas marcadamente más altas tanto de participación y de aprobación de las propuestas de impuestos sobre energía. Además, constató que hay otras características, como género e ingresos, que determinan la participación en los votos.

Rossi (2011) analiza la fiscalidad ambiental nacional y extranjera, para demostrar su importancia para el medio ambiente. con ejemplos internacionales de países como: Australia, Bélgica, Japón y Noruega, donde se pueden deducir gastos con prevención y control de la contaminación de los impuestos debidos, llama la atención también a los casos de Austria, Suiza y Turquía, donde inversiones para el aumento de la eficiencia energética pueden deducirse de los impuestos.

Otra investigación que merece destaque se refiere al trabajo desarrollado por Aidt (2010), este autor ha demostrado que en varios países de la unión europea la tributación ambiental contribuye a subsidiar inversiones en tecnologías limpias. Aidt (2010) entiende que los impuestos verdes (ambientales) pueden contribuir a internalizar las externalidades que impactan al medio ambiente, y su aumento de ingresos. Además sus estudios proporcionan subsidios para la comprensión sobre las reformas recientes de impuestos verdes en Europa. 
Así, la concepción de la tributación ambiental, presupone que está no debe ter como eje central los fines recaudatorios para el mantenimiento del estado. En definitiva, la tributación ecológica puede contribuir en esta dirección, mediante la adopción de incentivos que posibiliten compatibilizar el desarrollo económico con las mejoras de la calidad de vida en las ciudades y así caminar hacia un desarrollo sostenible. Por ejemplo, el Impuesto sobre la Propiedad Predial y Territorial Urbana (IPTU) puede contribuir en este sentido.

\subsection{IPTU Verde: instrumento extrafiscal de política urbana}

Por todo lo comentado, los municipios brasileños han utilizado el Impuesto sobre la Propiedad Predial y Territorial Urbana (IPTU) como mecanismo de propagación de la práctica de la conservación y preservación ambiental, esto se debe principalmente a que este tributo actúa como uno de los instrumentos de política urbana legalmente previsto en Brazil en el Estatuto de la ciudad, mediante la ley 10.257/2001. Es importante recordar que el IPTU es un impuesto de competencia municipal que afecta a las propiedades urbanas, potencial en el cumplimiento de la función social de la propiedad e importante para la financiación de la infraestructura local (Afonso, Araújo y Nóbrega, 2010; y Azevedo, 2017).

Jahnke, Willani e Araújo (2013, p. 420) recuerdan que, con la intención de incentivar el modelo sostenible, surgieron leyes municipales que versan sobre la posible reducción del IPTU cuando se constaten prácticas sostenibles, o que promuevan acciones beneficiosas para el medio ambiente. De Cesare, Fernandes y Cavalcanti $(2015$, p. 43) llaman la atención sobre el hecho de que las prácticas sostenibles realizadas en emprendimientos inmobiliarios pueden contribuir a la concesión de descuento en el IPTU. Esta previsión ha sido denominada IPTU verde o "ecológico". Así, en su vertiente ambiental, puede ser denominado IPTU verde, IPTU ecológico, IPTU ambiental, o IPTU sostenible. Todas estas denominaciones para indicar que este impuesto actúa como instrumento de política urbana en el incentivo a la adopción de prácticas de sostenibilidad ambiental como forma de contribuir a la función socio-ambiental de la propiedad urbana, además de posibilitar la motivación y estímulo a comportamientos en consonancia con la sostenibilidad ambiental.

Se ejemplifica como prácticas de sostenibilidad ambiental o criterios ambientales que se incorporarán a la incidencia del IPTU. La instalación de sistemas de captación de agua de lluvia, el reaprovechamiento del agua, la construcción de cubiertas vegetales, el reciclaje de residuos sólidos, la adopción de fuentes de energía limpias y renovables, la instalación de placas fotovoltaicas para la captación de energía solar en los inmuebles, la plantación de vegetación, y la conservación de áreas verdes en el inmueble y su entorno, la arborización, la manutención de parques y jardines públicos, acciones con vistas al reciclaje de residuos, la utilización de ladrillos ecológicos, madera de reforestación, construcciones sostenibles, representan todas ellas acciones de estímulo a la recuperación y preservación del medio ambiente por medio del IPTU verde (Bezerra, 2011; Dantas, 2014; De Cesare, Fernandes e Cavalcanti, 2015; y Castilho, 2016). A las prácticas mencionadas hay que añadir la plantación de árboles en aceras y la instalación de bicicletarios públicos, y no se puede olvidar de las prácticas descritas en los Objetivos del Desarrollo Sostenible (ODS) que pretende alcanzar el modo de vida en las ciudades. Por tanto la promoción de tales prácticas representa un gran potencial de colaboración entre la política urbana y fiscal (Azevedo, 2017). 
Dantas (2014, p. 84) recuerda que la regla-matriz del IPTU verde, puede ser redefinida y considerar también el elemento de exención o reducción de alícuotas. La exención se refiere a una limitación legal del acuerdo con la norma jurídica que impide que un tributo nazca, que surge como resultado de un favor fiscal, no propiciando pago de tributo. En el caso de la reducción, es la disminución de la alícuota de un impuesto. De este modo, la regla-matriz del IPTU verde, todos los criterios permanecen los mismos, excepto el elemento material, que será cualificado con los comportamientos que la entidad tributante pretende estimular por reputarlos adecuados a la protección y preservación del medio ambiente, y del criterio cuantitativo que será modificado. Esa modificación puede ocurrir mediante la norma de exención o a través del mecanismo de reducción de la alícuota. (Dantas, 2014, p. 84-85).

Reforzando la idea de extra fiscalidad tributaria con vistas al desarrollo sostenible, municipios brasileños, han adoptado, a partir del IPTU, incentivos fiscales en forma de descuentos, reducción o incluso exención, como propuesta para estimular a los propietarios de inmuebles a adoptar prácticas en beneficio del medio ambiente. Barros (2014) argumenta que la práctica del IPTU verde como beneficio tributario ha estimulado a la sociedad y a los municipios del país. Dice incluso que la ciudad sostenible no es una moda pasajera sino que deberá ser vista como actitud permanente y ser practicada por la administración pública a través de la gestión inteligente y de recursos renovables que incluyan el fomento a medidas de preservación y protección de los recursos naturales de la ciudad.

Barros (2014) recuerda que en Brazil la primera experiencia se dio en el municipio de São Carlos (Ley no 13.692/2005), con una población de 21.950 habitantes (IBGE, 2010). En esta ciudad se instituyeron incentivos fiscales ambientales atribuidos a los contribuyentes con comportamientos beneficiosos para el medio ambiente. La reglamentación incluye un capítulo dedicado a los incentivos ambientales (artículo 44), donde se discuten los beneficios que se concederán en forma de descuento en el valor del impuesto. Para ello, se aplica un descuento de hasta el $2 \%$ cuando se realizan las siguientes prácticas: a) plantación o manutención de árboles delante de los inmuebles de edificación horizontal y b) inmuebles que posean en el perímetro de su terreno áreas efectivamente permeables, con cubierta vegetal.

En el ámbito académico, ya es posible observar estudios que abordan la temática del IPTU verde en municipios brasileños. Por ejemplo, Passos y Pozzetti (2012) hicieron estudio sobre la extra fiscalidad ambiental del IPTU y presentaron el ejemplo del municipio de Manaus, en cuanto a la importancia de este impuesto en una perspectiva verde, y el estudio concluye que debería incluirse la planificación urbana en el impuesto con vistas al desarrollo sostenible.

Cunha, Martínez y Nossa (2013) analizaron y compararon los incentivos fiscales de los municipios de Vila Velha/ES, São Carlos/SP y Curitiba/PR. Específicamente en Curitiba/PR retrataron la evolución de los contribuyentes beneficiados por la reducción del IPTU en el espacio temporal que va de 2007 a 2011. Se hizo evidente que este beneficio ha aumentado en el municipio. En 2007 habían sido contemplados 12.877 contribuyentes; en 2011 este volumen aumentó a 17.006 beneficiarios. En cuatro años se produjo un aumento del $30 \%$ en el beneficio fiscal.

Los estudios de Piacentini, Pedro Filho y Almeida (2015), sobre las prácticas extra fiscales de gestión urbana sostenible, que analizan las regulaciones de IPTU verde en diez municipios brasileños. El estudio revela que en las ciudades encuestadas había similitud de legislaciones y 
normas, no propiciando un perfeccionamiento que resultara en instrumentos legales mejores que los ya practicados. Esas legislaciones no estaban en consonancia con las premisas de la sostenibilidad propuestas en la perspectiva conceptual que presupone equilibrio ambiental, social y económico. Finalmente, el estudio de Azevedo (2017) analiza los criterios y beneficios tributarios en materia de IPTU en el municipio de Salvador, propone componentes de tributación ecológica para este municipio y compara este instrumento tributario con dos contribuyentes.

A partir de los argumentos y estudios citados, se percibió que las investigaciones que abordan la temática IPTU verde en los municipios brasileños, priorizan discutir los aspectos centrales de la legislación que regula el beneficio fiscal, no entrando en cuestiones como comparación de los criterios de concesión y de los beneficios que se atribuyen a los contribuyentes, formato del beneficio tributario, divulgación del volumen y contabilización de los ingresos renunciados con su institución, y si este actúa como un instrumento de política urbana para el desarrollo sostenible.

Ante este contexto, el incentivo fiscal denominado IPTU verde, es una forma de renuncia a ingresos, que viene siendo utilizada en la gestión pública local, como uno de los instrumentos de la política urbana, en forma de beneficio fiscal, y se configura como ejemplo de aplicación de la extra fiscalidad tributaria stricto-sensu. EI IPTU verde (ecológico) puede ser caracterizado como una tentativa de que los municipios estimulen o induzcan prácticas que conlleven comportamientos en consonancia con el desarrollo sostenible en su dimensión ambiental. En este contexto, se consta que diversos ayuntamientos de Brazil han atribuido a los contribuyentes del IPTU la posibilidad de desarrollar acciones con vistas a la sostenibilidad y la comprobación de tales acciones culmina en la obtención de beneficios fiscales, en forma de exención, rebajas o descuentos en el valor del impuesto.

De esta manera, la expectativa central del estudio presupone que los incentivos fiscales verdes en materia de IPTU podrán actuar como instrumento de política urbana con vistas al desarrollo sostenible de las ciudades. .

\section{METODOLOGÍA Y ESTRATEGIA DE INVESTIGACIÓN}

El presente estudio es una investigación aplicada en cuanto a su naturaleza, ya que el trabajo presupone generación de conocimiento a efectos prácticos. Se trata de un estudio empírico con el fin de proporcionar objetivad y precisión a los resultados de la investigación.

El recorrido metodológico de la presente investigación se encuentra distribuido en tres etapas: la primera se refiere a la construcción de una plataforma teórica para la profundización sobre tributación ecológica, con especial énfasis en el IPTU bajo la óptica de las prácticas de sostenibilidad. En esta fase se recurrió a la técnica de la investigación de la documentación indirecta a través de búsqueda bibliográfica y documental. La investigación bibliográfica se apoya en libros, artículos publicados en periódicos científicos, tesis y tesinas que abordan el tema. Además, fue en esta etapa cuando fue establecida la expectativa central del estudio.

La segunda etapa se refiere a la caracterización de los procedimientos metodológicos para el desarrollo de esta investigación, de naturaleza descriptiva en cuanto a sus objetivos, dado que describe las posibilidades de adopción del IPTU verde en municipios brasileños. Se recurrió a la investigación documental para la verificación de legislaciones de la temática, publicadas en páginas web gubernamentales brasileñas. 
Se buscó comparar municipios brasileños en lo que se refiere a las regulaciones de los incentivos y beneficios fiscales ecológicos a partir del IPTU. Para ello, se optó por ciudades con población superior a $\mathbf{5 0 0 . 0 0 0 ~ h a b i t a n t e s , ~ d e b i d o ~ b a ́ s i c a m e n t e ~ a ~ l o s ~ r e f l e j o s ~ q u e ~ l a ~ i n t e n s i f i c a c i o ́ n ~}$ del uso y ocupación del suelo ocasiona en el medio ambiente. Estas ciudades fueron mapeadas por medio del contacto electrónico con los ayuntamientos y de la verificación electrónica, en páginas webs gubernamentales de entidades de apoyo a la diseminación y a la divulgación municipales, con el fin de identificar ciudades que poseyeran el IPTU verde o otro tipo de beneficio fiscal ecológico a partir de este impuesto. El levantamiento ocurrió de 01/12/2016 hasta 31/12/2016.

La tercera etapa del estudio consistió en el análisis específico de las legislaciones locales que versaban sobre beneficios tributarios ecológicos en materia de IPTU y su descripción. Se abordó el formato y vigencia del beneficio fiscal, en cuanto a las medidas de compensación adoptadas en función de la renuncia a los ingresos. Como estrategia de investigación, se recurrió al procedimiento de análisis de contenido.

\section{RESULTADO DEL ESTUDIO}

A partir de los datos recogidos, se procedió al análisis de la investigación con la finalidad de alcanzar los objetivos y dar respuesta al problema central del trabajo. Se exponen los resultados en dos sesiones: a) presentación general de IPTU en municipios brasileños, específicamente los de más de 500.000 habitantes; b) análisis de las posibilidades de adopción de tributación ecológica en materia de IPTU.

\subsection{IPTU verde en municipios brasileños}

El estudio comprobó que, cuando la realización de esta investigación que de los 5.571 municipios (IBGE, 2010), existían e al menos 24 municipios brasileños con población de entre 30.000 y 500.000, que instituyeron descuentos con reducción en el valor del IPTU para contribuyentes que adoptasen medidas para el estímulo a la conservación y preservación del medio ambiente en sus propiedades con vistas a la sustentabilidad.

En el estudio en los municipios con más de 500.000 habitantes, existían en 31/12/2016, 38 con cuantitativo superior poblacional superior al indicado (IBGE, 2010), los cuales fueron objeto de verificación en cuanto a la existencia de reglamentación del IPTU verde. Para ello, se verificó si la puesta en práctica de las medidas descritas en las legislaciones converge, en cuanto a los criterios de cobertura, con los presupuestos de la dimensión ambiental de la sostenibilidad.

Se constató, por ejemplo que el municipio de São Paulo tiene la mayor población de Brasil, sin embargo en el apartado de densidad de población ocupa la 36ạ posición, y ocupa la 7ạ posición de Brasil en área territorial. Las ciudades de Osasco y Fortaleza son las que tienen mayor concentración urbana en este aspecto, aunque el área territorial en km2 es una de las 10 menores de Brasil. El caso del municipio de Salvador tiene una densa ocupación, en 2010 era la tercera capital en población de Brasil, su área territorial ocupaba la 17ạ posición en relación a los municipios con más de 500.000 habitantes y su densidad de población por km2 representaba la 20a posición al compararla con otros municipios. 
De los 38 municipios, se obtuvieron datos de 26 localidades. Hubo 12 que a fecha del cierre de este estudio no contestaron las solicitudes. De tal forma, el universo de la investigación comprendió 26 municipios. De estos, 17 tienen algún tipo de beneficio o incentivo fiscal verde a partir del IPTU, 3 tienen proyectos de ley en trámite en la Cámara Municipal y 1 municipio ha publicado una Ley para el beneficio fiscal a partir del impuesto pero se encuentra a la espera de reglamentación. El Cuadro 1 destaca las reglamentaciones del beneficio fiscal verde:

Cuadro 1 - Municipios con legislación local de beneficios fiscales ambientales en materia de IPTU

\begin{tabular}{|c|c|c|c|}
\hline Cant. & Municipio & Reglamentación local & Alcance y amplitud de la reglamentación \\
\hline 01 & Campinas & $\begin{array}{l}\text { Ley } n=11.111 / 2001 \\
\text { Decreto no } 16.274 / 2008\end{array}$ & $\begin{array}{l}\text { Proprietarios de Areas de Preservación Ambiental } \\
\text { Permanente (APP) }\end{array}$ \\
\hline 02 & $\begin{array}{l}\text { Campo } \\
\text { Grande }\end{array}$ & $\begin{array}{l}\text { Ley complementaria } \\
\text { no } 150 / 2010 .\end{array}$ & $\begin{array}{l}\text { Propietarios de inmuebles residenciales y comerciales } \\
\text { que adopten prácticas de sostenibilidad ambiental. }\end{array}$ \\
\hline 03 & Cuiabá & $\begin{array}{l}\text { Ley complementaria no } \\
004 / 92 \text {, Artículo } 554\end{array}$ & $\begin{array}{l}\text { Inmuebles localizados en áreas verdes de Areas de } \\
\text { Preservación Ambiental Permanente (APP's) y Zonas } \\
\text { de Interés Ambiental (ZIAS) }\end{array}$ \\
\hline 04 & Curitiba & $\begin{array}{l}\text { Ley Complementaria no } \\
\text { 9.806/2000 - Código } \\
\text { Forestal del municipio de } \\
\text { Curitiba. }\end{array}$ & $\begin{array}{l}\text { Áreas de preservación ambiental - terrenos } \\
\text { integrantes del sector especial de áreas verdes y } \\
\text { protección a bosques nativos y bosques nativos } \\
\text { relevantes. }\end{array}$ \\
\hline 05 & $\begin{array}{l}\text { Feira de } \\
\text { Santana }\end{array}$ & Ley no 3.506/2014 & $\begin{array}{l}\text { Propietarios de inmuebles residenciales y no } \\
\text { residenciales que adopten prácticas de sostenibilidad } \\
\text { ambiental. }\end{array}$ \\
\hline 06 & Goiânia & $\begin{array}{l}\text { Ley complementaria no } \\
\qquad 235 / 2012\end{array}$ & $\begin{array}{l}\text { Contribuyentes del IPTU de inmuebles edificados que } \\
\text { desarrollen acciones que promuevan el ideario de la } \\
\text { ciudad sostenible, con vistas a la mejoría de la calidad } \\
\text { de vida de los habitantes y minimizar el impacto en el } \\
\text { medio natural por medio de la adopción de prácticas } \\
\text { de sostenibilidad ambiental. }\end{array}$ \\
\hline 07 & Guarulhos & $\begin{array}{l}\text { Ley no } 6.793 / 2010 \text { y } \\
\text { Decreto no } 28.696 / 2011\end{array}$ & $\begin{array}{l}\text { Propietarios o poseedores: a) de inmuebles edificados } \\
\text { horizontales que posean de uno o más árboles delante } \\
\text { del edificio; b) inmuebles edificados horizontales; } \\
\text { c)inmuebles que adopten prácticas de sostenibilidad } \\
\text { ambiental; d) Áreas de Preservación Ambiental } \\
\text { Permanente (APAP); e) inmuebles edificados o no que } \\
\text { participen del programa "Acera ciudadana" } \\
\text { (construcción, reconstrucción y manutención de las } \\
\text { aceras de las vías públicas). }\end{array}$ \\
\hline 08 & Londrina & Ley no 11.996/2013 & $\begin{array}{l}\text { Plan director de arborización - estimula a los } \\
\text { propietarios o poseedores de terrenos integrantes del } \\
\text { sector especial de áreas verdes (bosques de } \\
\text { preservación permanente) a la preservación de estas } \\
\text { áreas. }\end{array}$ \\
\hline 09 & Manaus & $\begin{array}{l}\text { Ley no 1.628/2011. Ley no } \\
886 / 2005\end{array}$ & $\begin{array}{l}\text { Área del inmueble reconocida por el poder público } \\
\text { municipal como Reserva Particular del Patrimonio } \\
\text { Natural - RPPN }\end{array}$ \\
\hline 10 & Natal & $\begin{array}{l}\text { Código Tributario } \\
\text { Municipal, Artigo } 44 .\end{array}$ & $\begin{array}{l}\text { Incentivo a áreas no edificables de conservación y } \\
\text { preservación ambiental, de acuerdo con lo definido } \\
\text { por el plan director de la ciudad. }\end{array}$ \\
\hline
\end{tabular}




\begin{tabular}{|c|c|c|c|}
\hline 11 & $\begin{array}{l}\text { Porto } \\
\text { Alegre }\end{array}$ & $\begin{array}{c}\text { Ley complementaria no } \\
\text { 07/73, (Artigo 70, XIX). } \\
\text { Ley Complementaria no } \\
\text { 396/96, no 5.416/2006 y } \\
\text { no 16.500/2009. Ley no } \\
\text { 14.265/03. }\end{array}$ & $\begin{array}{l}\text { Áreas de Interés Ambiental (inmueble, o parte de él, } \\
\text { reconocido como Reserva Particular del Patrimonio } \\
\text { Natural; Áreas de Preservación Permanente; c) Áreas } \\
\text { de Protección del Ambiente natural; d) y otras áreas } \\
\text { de interés ambiental; siempre y cuando se mantengan } \\
\text { preservadas de acuerdo a los criterios establecidos por } \\
\text { la Secretaría municipal del medio ambiente. }\end{array}$ \\
\hline 12 & $\begin{array}{l}\text { Rio de } \\
\text { Janeiro }\end{array}$ & $\begin{array}{l}\text { Ley no 691/84 (Artigo 61) } \\
\text { y Ley no } 792 / 1985\end{array}$ & $\begin{array}{l}\text { Terrenos y edificios de interés ecológico, paisajístico, } \\
\text { ambiental, reservas forestales o terrenos con bosques } \\
\text { de área superior a } 10.000 \mathrm{~m} 2 \text {. }\end{array}$ \\
\hline 13 & $\begin{array}{l}\text { São } \\
\text { Bernardo } \\
\text { do Campo }\end{array}$ & Ley no 6.091/2010 & $\begin{array}{l}\text { Inmuebles con cubierta vegetal o destinada a la } \\
\text { producción horti-frutícola. }\end{array}$ \\
\hline 14 & Salvador & $\begin{array}{c}\text { Ley } \mathrm{n} \text { o } 8.473 / 2013 . \\
\text { Decreto } \\
\text { no } 25.899 / 2015\end{array}$ & $\begin{array}{l}\text { Inmuebles que adoptan medidas que estimulen la } \\
\text { protección, preservación y recuperación del medio } \\
\text { ambiente, acciones y prácticas sostenibles. }\end{array}$ \\
\hline 15 & São Paulo & Ley no 10.365/1987 & $\begin{array}{l}\text { Protección ambiental - inmuebles revestido de } \\
\text { vegetación arbórea declarada de preservación } \\
\text { permanente o perpetuada; Área de Protección a las } \\
\text { Fuentes. }\end{array}$ \\
\hline 16 & Sorocaba & Ley no 9.571/2011 & $\begin{array}{l}\text { Nuevos inmuebles residenciales, incluyendo los } \\
\text { edificios horizontales y edificios que adopten prácticas } \\
\text { de sostenibilidad ambiental, y las viviendas } \\
\text { sostenibles. }\end{array}$ \\
\hline 17 & Uberlândia & Ley n $10.700 / 2011$ ) & $\begin{array}{l}\text { Áreas urbanas plantadas o mantenidas con esencias } \\
\text { nativas arbóreas, de uso privado o que fueren abiertas } \\
\text { al uso público, sin cargas para el municipio } \\
\text { Reaprovechamiento de aguas pluviales. }\end{array}$ \\
\hline
\end{tabular}

Fuente: Elaborado por los autores.

Se constató que los municipios que adoptan alguna práctica de incentivo a la protección y conservación del medio ambiente, han dirigido a la forma del beneficio fiscal al contribuyente a partir del IPTU, incentivando: a) la conservación de las Áreas: RPPN, Preservación Permanente, Reserva Legal (RL), de APA, de Área de Unidad de Conservación del Dominio Público (UCDP), Área de Interés Ecológico (AIE), Bosques o Reservas Cubiertas por Áreas de Bosques Nativos (AFN), Áreas bajo el régimen de Servidumbre Forestal o Ambiental (ASFA); b) prácticas de sostenibilidad ambiental; y c) edificaciones que promuevan el aumento de las aceras y la arborización en las vías públicas.

Con relación a las prácticas de sostenibilidad ambiental específicamente, fue posible comprobar en las ciudades de Campo Grande (MTS), Feira de Santana (BA), Goiânia (GO), Guarulhos (SP), Salvador (BA), y Sorocaba (SP) las siguientes acciones: a) sistema de captación y reutilización de aguas pluviales o oriundas de otras fuentes; b) sistema de calentamiento hidráulico solar; c) sistema de calentamiento eléctrico solar, energía pasiva y sistema de utilización de energía eólica; d) construcciones y edificación con material sostenible; e) construcción de tejado verde; f) construcción de aceras ecológicas o verdes, así como su adaptación para el tránsito libre y seguro; g) arborización de aceras plantadas con especies arbóreas nativas; h) permeabilidad del suelo con cubierta vegetal; i) adopción de recolección selectiva y destinación de los residuos sólidos para empresas y cooperativas de reciclaje. 
En el municipio de Salvador la legislación local estableció criterios para la certificación de los contribuyentes para fines de obtención del beneficio tributario y hubo modificaciones de la misma, específicamente en noviembre/2017. Debido a que dichas modificaciones no alcanzaron el lapso temporal de este estudio, no serán objeto de discusión en el presente trabajo.

Las prácticas de sostenibilidad ambiental citadas, hay que comentar que el municipio de Guarulhos (SP) adopta el incentivo para llevar a los contribuyentes del IPTU a participar en la construcción, reconstrucción y manutención de las aceras de vías públicas. Lo mismo ocurre en São Bernardo do Campo (SP), que viene incentivando a los propietarios de inmuebles residenciales a la producción horti-frutícola en residencias y que se comercializa en la ciudad.

\subsection{Análisis de la de adopción de tributación ecológica en materia de IPTU}

La adopción de tributación ecológica en materia de IPTU se presenta en la forma de, exenciones, descuentos, reducciones de este impuesto. Se constató en las 17 ciudades investigadas, que 6 municipios aplican exención de IPTU, y los demás conceden descuento o reducción en el valor del mismo. El Cuadro 2 muestra el formato del beneficio fiscal en cuanto su formato.

\section{Cuadro 2 - Formato del Beneficio Fiscal}

\begin{tabular}{|c|c|c|}
\hline Municipio & Formato del beneficio fiscal & Tiempo de vigencia \\
\hline Campinas & Exención entre el $15 \%$ y el $100 \%$ del IPTU. & No se menciona \\
\hline Campo Grande & Reducción del IPTU que varía entre el $4 \%$ y el $10 \%$. & $\begin{array}{l}\text { Tres años, pudiendo ser } \\
\text { renovado }\end{array}$ \\
\hline Cuiabá & Reducción del 20\% al 80\% del valor del IPTU. & No se menciona \\
\hline Curitiba & $\begin{array}{l}\text { Exención o reducción sobre el valor del terreno para } \\
\text { base de cálculo del impuesto; siendo proporcional a } \\
\text { la tasa de cubierta forestal del terreno que variará } \\
\text { entre el } 10 \% \text { y el } 100 \% \text {. }\end{array}$ & No se menciona \\
\hline $\begin{array}{ll}\text { Feira de } \\
\text { Santana }\end{array}$ & $\begin{array}{l}\text { a) Reducción del impuesto en hasta el } 20 \% \text { en las } \\
\text { acciones de preservación, protección y recuperación } \\
\text { del medio ambiente; b) exención para las APP. }\end{array}$ & No se menciona \\
\hline Goiânia & $\begin{array}{l}\text { Descuento del IPTU del } 3 \% \text { y el } 20 \% \text { siempre que } \\
\text { adopten un mínimo de } 2 \text { o más acciones en la } \\
\text { legislación local. }\end{array}$ & No se menciona \\
\hline Guarulhos & $\begin{array}{l}\text { a) Descuento del IPTU del } 2 \% \text { al } 20 \% \text { de acuerdo con } \\
\text { las acciones indicadas en el artículo } 2 \text { de la ley; b) } \\
\text { descuento de hasta el } 5 \% \text { en el valor anual del IPTU } \\
\text { a los contribuyentes que participen en el programa } \\
\text { "Acera ciudadana"; c) exención del impuesto para las } \\
\text { APP. }\end{array}$ & $\begin{array}{l}\text { Se menciona en el Art. } 117 \\
\text { que la concesión de los } \\
\text { beneficios no genera } \\
\text { derecho adquirido y podrán } \\
\text { ser anulados a tiempo. }\end{array}$ \\
\hline Londrina & $\begin{array}{l}\text { 100\% de reducción en el IPTU para cubierta forestal } \\
\text { de más del } 70 \% \text {, es decir, exención. Hay } \\
\text { reducciones que varían entre el } 5 \% \text { y el } 80 \% \text { en } \\
\text { función del área de cubiertas forestar en áreas } \\
\text { verdes nativas de la región }\end{array}$ & No se menciona \\
\hline Manaus & $\begin{array}{l}\text { Exención del IPTU a los inmuebles integrantes de la } \\
\text { Reserva Particular del Patrimonio Natural, RPPN. }\end{array}$ & No se menciona \\
\hline Natal & Reducción de la alícuota del impuesto hasta el 0\%. & No se menciona \\
\hline Porto Alegre & Exención del pago del IPTU. & No se menciona \\
\hline
\end{tabular}




\begin{tabular}{|c|c|c|}
\hline Rio de Janeiro & Exención del pago del IPTU & No se menciona \\
\hline Salvador & $\begin{array}{l}\text { Descuento en el valor del IPTU, entre el } 5 \text { y el } 10 \% \text { en } \\
\text { las inscripciones de cada unidad inmobiliaria del } \\
\text { emprendimiento, según la certificación. }\end{array}$ & $\begin{array}{l}\text { Tres años pudiendo ser } \\
\text { renovado el beneficio por } \\
\text { igual período, es decir, } \\
\text { podrá disfrutar de hasta } 6 \\
\text { años de beneficio fiscal. }\end{array}$ \\
\hline $\begin{array}{l}\text { São Bernardo } \\
\text { do Campo }\end{array}$ & Reducción del 80\% de la alícuota del IPTU. & $\begin{array}{l}\text { Años consecutivos después } \\
\text { del término del beneficio, } \\
\text { se prevé que el } \\
\text { contribuyente pueda } \\
\text { requerir nuevamente el } \\
\text { beneficio fiscal. }\end{array}$ \\
\hline São Paulo & Descuento de hasta el 50\% del valor del impuesto. & No se menciona \\
\hline Sorocaba & $\begin{array}{l}\text { Descuento del } 10 \% \text { en el IPTU a los nuevos inmuebles } \\
\text { que adopten prácticas de sostenibilidad ambiental. }\end{array}$ & $\begin{array}{l}\text { El contribuyente pedirá } \\
\text { anualmente la renovación } \\
\text { del beneficio tributario. }\end{array}$ \\
\hline Uberlândia & $\begin{array}{l}\text { Reducción del valor del impuesto: a) de hasta el } 50 \% \\
\text { a las áreas urbanas plantadas o mantenidas con } \\
\text { especies nativas arbóreas, de uso privado; b) de } \\
\text { hasta el } 100 \% \text { de su calor se fuesen abiertas al uso } \\
\text { público sin cargas para el municipio. } \\
\text { Descuentos: } 30 \% \text { considerando la cantidad de agua } \\
\text { reaprovechada en la edificación con vistas a un uso } \\
\text { racional de la misma. }\end{array}$ & No se menciona \\
\hline
\end{tabular}

Fuente: Elaborado por los autores.

El Cuadro 2 permite constatar que en las 17 ciudades hay una preferencia por instituir beneficio fiscal en forma de descuento o reducción del impuesto. Las ciudades que introdujeron medidas de sostenibilidad ambiental específicamente (Guarulhos/SP, Goiânia/GO, Salvador/BA, y Sorocaba /SP) vienen concediendo descuentos que varían entre el $2 \%$ y el $20 \%$ del valor del IPTU. Campo Grande/MTS y Feira de Santana/BA adoptan la reducción del valor del impuesto, variando entre el $4 \%$ y el $20 \%$. Así, según las referencias teóricas estudiadas, esta perspectiva puede ser considerada como lo que se denomina IPTU verde. Por lo que se refiere a la vigencia del beneficio tributario se constató que cuatro municipios mencionan este aspecto en sus legislaciones.

Aunque el beneficio fiscal verde atribuido al IPTU en Curitiba no esté en su totalidad integrada a las prácticas de sostenibilidad ambiental, posibilita la preservación y conservación ambiental (áreas verdes con cubierta forestal), como bosque nativo, pinos y árboles de copa extensa. Su Código Forestal, con el fin de estimular un comportamiento sostenible, introdujo en su legislación la previsión de exentar o reducir este impuesto, que varía entre el $20 \%$ y el $100 \%$, dependiendo de la situación. Esta reducción del impuesto es concedida al contribuyente que tenga su propiedad registrada en el catastro municipal como inmueble con bosque relevante.

El incentivo fiscal atribuido al municipio de Curitiba tiene un carácter restringido, pues estimula solo comportamientos para la conservación, preservación y protección de áreas integrantes del Sector Especial de Áreas Verdes, que engloba APA y bosque nativos de la ciudad. De forma similar se observa en los municipios de Cuiabá, Manaus, Porto Alegre, Río de Janeiro y São 
Bernardo do Campo, que atribuyen exenciones del IPTU a inmuebles que estén en áreas de interés y preservación permanente ambiental y áreas forestales.

En Guarulhos S/P, mediante la Ley Municipal no 6.793/2011, que regula el IPTU, hay experiencia en relación con el impuesto verde. Esta legislación dedica un capítulo específico para disciplinar los incentivos ambientales. Así, los Artículos 60 y 61 prevén la posibilidad de descuentos en el valor anual del IPTU de los inmuebles que adopten medidas ambientales. Para atribuir el descuento en el IPTU fue adoptado un sistema de acuerdo con la acción de sostenibilidad desarrollada, pudiendo así obtener el contribuyente hasta un $20 \%$ de descuento en forma de beneficio fiscal. En esta localidad no hay sistema de puntuación para graduar el descuento en el municipio.

El descuento en el IPTU en Guarulho/SP se da en función de las opciones de sostenibilidad que repercuten directamente en los propietarios de inmuebles, pero tienen también beneficios para la población. El Cuadro 3 demuestra las prácticas para obtener el descuento del IPTU.

Cuadro 2 - Criterios para descuentos del IPTU en Guarulhos/SP con la adopción de medidas ambientales

\begin{tabular}{|c|c|}
\hline Descripción & $\begin{array}{l}\text { Porcentaje de } \\
\text { descuento }\end{array}$ \\
\hline $\begin{array}{l}\text { Inmuebles edificados horizontales (excepto lugares de recreo) que posean uno o } \\
\text { más árboles delante del inmueble, de acuerdo con los tipos adecuados para la } \\
\text { arborización de vías públicas. }\end{array}$ & $2 \%$ \\
\hline $\begin{array}{l}\text { Preservación de árboles ya existentes, observando el mantenimiento del área } \\
\text { suficiente para su riego. }\end{array}$ & $2 \%$ \\
\hline $\begin{array}{l}\text { Inmuebles edificados horizontales (excepto lugares de recreo) que posean en el } \\
\text { perímetro de su terreno áreas efectivamente permeables, con cubierta vegetal. }\end{array}$ & $2 \%$ \\
\hline $\begin{array}{l}\text { Edificios construidos horizontalmente o verticales (excepto lugares de recreo) que } \\
\text { posean en el perímetro de su terreno áreas efectivamente permeables, con cubierta } \\
\text { vegetal. }\end{array}$ & $1 \%$ \\
\hline $\begin{array}{l}\text { Inmuebles edificados horizontalmente que conserven la acera en condiciones } \\
\text { favorables para el acceso de ancianos y personas con alguna discapacidad. }\end{array}$ & $5 \%$ \\
\hline Sistema de captación del agua de lluvia. & $3 \%$ \\
\hline Sistema de reutilazación del agua & $3 \%$ \\
\hline Sistema de calefacción hidráulico solar. & $3 \%$ \\
\hline Construcciones con material sostenible. & $3 \%$ \\
\hline Utilización de energía passiva & $3 \%$ \\
\hline Instalación de energía eólica. & $5 \%$ \\
\hline Instalación de tejado verde en todos los tejados del inmueble. & $3 \%$ \\
\hline $\begin{array}{l}\text { Separación de residuos sólidos de los edificios horizontales o verticales que, de } \\
\text { forma comprobada, destinen la basura recogida para el reciclaje y el } \\
\text { aprovechamiento. }\end{array}$ & $5 \%$ \\
\hline
\end{tabular}

Fuente: Elaborado por los autores, a partir de la Ley no 6.793/2011

Se puede constatar que Guarulhos/SP, al instituir el IPTU verde, buscó en la extra fiscalidad inducir comportamientos de los contribuyentes del IPTU, por medio del estímulo a la adopción de prácticas de sostenibilidad con énfasis en la dimensión ambiental. Como se observa, hace más de diez prácticas que los detentores de inmuebles de este municipio pueden adoptar, y así obtener el beneficio fiscal. Esta legislación indica que no es posible acumular descuentos en una misma práctica 
adoptada. Para ampliar el porcentaje de descuento, el contribúyete deberá diversificar las acciones con reflejo ambiental, y el descuento no podrá nunca ser superior al $20 \%$.

En Salvador/BA, la legislación del IPTU verde es compleja y dificulta el acceso de los contribuyentes del IPTU al beneficio tributario. En la capital bahiana, el ayuntamiento atribuye una serie de exigencias para el encuadramiento de este incentivo fiscal, imponiendo esfuerzos y costos financieros para que el contribuyente desarrolle prácticas de sostenibilidad, para la obtención de la certificación de emprendimiento sostenible y la respectiva aplicación del descuento en el impuesto. Hasta el cierre del estudio sólo un contribuyente de este impuesto obtuvo el descuento por adoptar prácticas de sostenibilidad ambiental en la edificación. El valor del descuento en el año de 2016 fue de $\mathrm{R} \$ 6.742,38$. Es válido registrar, que aunque no alcance el período de la investigación, el municipio tuvo una modificación en la legislación de este incentivo tributario en noviembre / 2017, con la publicación del decreto № 29.100/2017.

Respecto a los requisitos legales para establecer la renuncia de ingresos, sólo las legislaciones de los municipios de Campo Grande (MTS), Feira de Santana (BA) y Sorocaba (SP), mencionan en sus legislaciones locales las medidas de compensación que serán adoptadas. Además, los municipios investigados, no demuestran la contabilización de la concesión de este tipo de beneficio tributario atribuidos a los contribuyentes del IPTU.

En cuanto al órgano responsable de aprobar, dar seguimiento y fiscalizar el IPTU Verde, se constató que en los municipios investigados esta atribución ha sido encargada a la Secretaría de Medio Ambiente, Planificación o Desarrollo Urbano, o Hacienda. Solo en Salvador/Ba se constató la participación de empresa del sector privado en la condición de evaluadores de las solicitudes del beneficio fiscal.

Se observa que en 2013 el municipio de Jaboatão dos Guararapes publicó ley que alteró el Código Tributario Municipal (CTM). Esta legislación tiene por objetivo introducir medidas ambientales a ser adoptadas por inmuebles con vistas a la reducción del IPTU. No obstante, hasta el cierre de este estudio, la legislación no había entrado en vigor, a la espera de reglamentación del asunto.

Además hay que subrayar que en el municipio de Río de Janeiro el incentivo ambiental no corresponde a las premisas de aplicación del IPTU verde. Hasta el cierre de este trabajo había un Proyecto de Ley (PL) no 1.027/2014 de noviembre/2014, en trámite en la Cámara Municipal de la ciudad, para la institución y reglamentación del beneficio fiscal con énfasis en medidas ambientales. Este PL prevé descuentos de entre un $2 \%$ y un $25 \%$ en el valor del impuesto. Otros ejemplos de municipios con más de 500.000 habitantes que tienen proyectos de esta naturaleza en trámite, son Belo Horizonte y São Paulo.

Además, el estudio reveló que en la mayoría de los municipios encuestados, los incentivos fiscales verdes en materia de IPTU presentan restricciones para actuar como instrumento de política urbana para el desarrollo sostenible en las ciudades, debido básicamente a las limitaciones para estimular a los contribuyentes propiciando condiciones y medios accesibles para la obtención de este beneficio tributario y criterios que prioricen la calidad de vida urbana. Este contexto reclamará una profunda reformulación en sus normas para definir componentes integrados con los Objetivos del Desarrollo Sostenible (ODS) para las ciudades, por ejemplo. 


\section{CONSIDERACIONES FINALES}

La creciente exigencia social respecto a las respuestas de los gobernantes al impacto que la presión del uso y ocupación del suelo causa en el medio ambiente. Este escenario comporta una serie de problemas con interferencias para las ciudades, por ejemplo la ampliación de construcciones irregulares e incluso ilegales, el precario saneamiento básico en áreas menos favorecidas, la expansión de las áreas de riesgos de derrumbamiento, el aumento de vertidos irregulares de residuos en locales inapropiados, además de la desaparición de áreas verdes y la reducción significativa de la arborización en vías públicas.

En este sentido, el poder público local, podrá valerse de una planificación urbana que posibilite mejorar la calidad de vida cotidiana y así minimizar los efectos derivados de tales presiones - y el IPTU podrá ser un útil instrumento de política urbana, en esta dirección. Específicamente con la adopción de la extra fiscalidad en su vertiente stricto sensu, con la integración de la tributación ecológica en materia de IPTU con las premisas de los ODS para las ciudades, para ayudar a los municipios a adoptar prácticas y tecnologías con vistas una ciudad sostenible.

En las evidencias empíricas encontradas, puede percibirse que los municipios de Brasil con más de 500.000 habitantes, 17 estimulan a los contribuyentes a proteger la conservación de los bosques y la naturaleza; prácticas de sostenibilidad ambiental; y promoción del aumento de las aceras y la arborización en las vías públicas edificadas. Para ello, se utilizan de instrumentos tributarios en forma de incentivos fiscales, con la reducción, descuento o exención del IPTU.

Los objetivos propuestos en el artículo han sido alcanzados levantando la discusión que engloba la mayoría de los municipios encuestados. Los incentivos fiscales verdes en materia de IPTU presentan restricciones para actuar como instrumento de política urbana para el desarrollo sostenible en las ciudades, debido básicamente a sus limitaciones para propiciar a los contribuyentes condiciones y medios accesibles para la obtención de este beneficio tributario y criterios que prioricen la calidad de vida urbana.

Respecto a la discusión de la adopción de tributación ecológica en el contexto de las prácticas de sostenibilidad ambiental, los municipios de este estudio indican amplias posibilidades como criterios ambientales que se incorporarán a la incidencia del IPTU. En el caso específico de este impuesto, no se constató la integración de las premisas de los ODS para las ciudades.

Al analizar las legislaciones locales que versan sobre beneficios tributarios ecológicos en materia de IPTU, se constató que vienen concediendo descuentos o reducción del impuesto que varían entre el $2 \%$ y el $20 \%$ del valor del IPTU. Se comprobó que Salvador/BA, es la única ciudad de Brasil con reglamentación del IPTU verde compleja y con dificultad del acceso de los contribuyentes al beneficio tributario.

Se concluye que la investigación fue relevante, tanto para el medio académico como para el gubernamental, pues su recorte permite profundizar en la tributación ecológica específicamente en lo que respecta al incentivo fiscal del IPTU verde.

Y para finalizar, se recomiendan futuros estudios con relación a los requisitos legales para establecer la divulgación de la renuncia de ingresos y metodologías para contabilización de la concesión de este tipo de beneficio tributario atribuidos a los contribuyentes del IPTU. 
Investigaciones que analicen si la modificación ocurrida en la legislación del IPTU Verde del municipio de Salvador contribuye a mejoras de la política urbana local.

Por último, se sugieren investigaciones en el sentido de ampliar de manera sistemática el beneficio fiscal en forma de reducción o descuento en el valor de otros impuestos, por ejemplo, el ISS de las empresas que adopten prácticas en consonancia con los ODS, específicamente: gestión de residuos, ampliación y acceso de espacios públicos y áreas verdes, gestión de las aguas y sistemas alternativos de eficiencia energética (micro y pequeña generación de energía solar).

\section{REFERÊNCIAS}

Afonso, J. R. R., Araújo, E. A., \& Nóbrega, M. A. R. D. (2013). O IPTU no Brasil: um diagnóstico abrangente. v. 4, FGV Projeto. Recuperado en 20 septiembre, 2016, de <http://fgvprojetos.fgv.br/sites/fgvprojetos.fgv.br/files/iptu_no_brasil_um_diagnostico_abrangen te_0.pdf $\geq$.

Aidt, T. S. (2010). Green taxes: Refunding rules and lobbying. Journal of environmental economics and management, 60(1), 31-43.

AYDOS, E. D. L. P. (2010). Tributação Ambiental no Brasil: Fundamentos e Perspectivas. 2010 (Doctoral dissertation, Dissertação (Mestrado)-Curso de Direito, Universidade Federal de Santa Catarina, Florianópolis, 2010. en 16 diciembre, 2014, de < http://www. egov. ufsc. br/portal/sites/default/files/anexos/33953-4473PB. pdf>. Acesso em: 01 jun).

Azevedo, T. C. (2017). Tributação municipal como incentivo ao desenvolvimento sustentável nas cidades: o caso do IPTU verde de Salvador. Tese de Doutorado. Universidade Católica do Salvador. Doutorado em Planejamento Territorial e Desenvolvimento Social. Salvador/BA, Brasil

Barros, S. (2014) IPTU Verde. Recuperado en 16 diciembre, 2014, de <http://silviobarros.com.br/site/noticia/325\#nav>.

Bezerra, P. I. S. (2011). Utilização dos Incentivos Fiscais como mecanismo para promover a sustentabilidade ecológica. Revista da Faculdade de Direito, Belo Horizonte, n. 59, p. 307-336, jul./dez.

Brasil, (1988). Constituição da República Federativa do Brasil de 1988. Recuperado en 22 noviembre, 2014 de <http://www.planalto.gov.br/ccivil_03/Constituicao/Constituicao.htm>.

Brasil. (2001). Lei no 10.257, de 10 de julho de 2001: Estatuto da Cidade. Regulamenta os arts. 182 e 183 da Constituição Federal, estabelece diretrizes gerais da política urbana e dá outras providências. Diário Oficial da União. Brasília. Recuperado en 04 de agosto, 2015, de <http://www.planalto.gov.br/ccivil_03/leis/LEIS_2001/L10257.htm

Buñuel González, M. (2004). Tributación medioambiental: teoría, práctica y propuestas. Madrid (España): Civitas Ediciones.

Castilho, A. F. D. A. N. (2016). A extrafiscalidade no Brasil. Revista Jurídica Luso Brasileira. v. 4, a. 2, p. 1135-159, ISSN: 2183-539X, Lisboa. 
Costa, R. H. (2011) Apontamentos sobre tributação ambiental. Lusíada. Direito e Ambiente, n. 2/3, Lisboa, 2011. Recuperado en 19 septiembre, 2016 de <http://revistas.lis.ulusiada.pt/index.php/lda/article/view/2142>.

Cunha, D. S. A.; Martinez, A. L.; Nossa, V. (2013) Incentivos Fiscais Verdes e Tributação Extrafiscal: Estudo Sobre o IPTU Verde no Município de Vila Velha (ES) Comparativamente a Outros Municípios. Revista Razão Contábil \& Finanças, v. 4, n. 1. Universidade Federal da Paraíba. Paraíba.

Dantas, G. T. (2014). O IPTU verde como instrumento de efetividade da função socioambiental da propriedade privada urbana. 2014. 144 f. Dissertação (Mestrado) - Universidade Federal da Bahia, Faculdade de Direito.

De Cesare, C. M., Fernandes, C. E. Cavalcanti, C. B. (2015). Imposto sobre a Propriedade Predial e Territorial Urbana. (Orgs.). Caderno Técnico de Regulamentação e Implementação de Instrumentos do Estatuto das Cidades. Brasília, DF: Ministério das cidades, Recuperado en 22 agosto, 2016 de $<$ http://www.capacidades.gov.br/biblioteca/detalhar/id/336/titulo/imposto-sobre-a-propriedadepredial-e-territorial-urbana-iptu>.

Gordilho, H. J. D. S. (2009) Direito ambiental pós-moderno. Curitiba: Juruá.

Herrera, M. P. (2000). Derecho tributario ambiental. Madrid: Marcial Pons Recuperado en 20 agosto de 2015, de <http://ssrn.com/abstract=1809637>. 2015

IBGE. Instituto brasileiro de geografia e estatística (2010). População 2010. Recuperado en 6 june, 2016, de <http://www.cidades.ibge.gov.br/xtras/uf.php?lang=\&coduf=29\&search=bahia>.

Jahnke, L. T., Willani, S. M. U. De Araújo, T. L. R.(2013). O IPTU verde: práticas sustentáveis trazem benefícios financeiros à população. Revista Eletrônica do Curso de Direito da UFSM, v. 8, p. 413-423. Recuperado en 20 mayo, 2016, de <http://periodicos.ufsm.br/index.php/revistadireito/article/view/8341/0\#.V3D1NfkrLIU>.

Montero, C. E. P. (2013) O Fundamento e a Finalidade Extrafiscal dos Tributos Ambientais. Revista de Direito da Cidade, v. 5, n. 2, p. 316-364. Recuperado en 20 mayo, 2016, de <http://www.epublicacoes.uerj.br/index.php/rdc/article/view/9960>.

Montero, C. E. P., (2011) Extrafiscalidade e meio ambiente: O tributo como instrumento de proteção ambiental, Reflexões sobre a tributação ambiental no Brasil e na Costa Rica. $306 \mathrm{f}$. Tese de Doutorado. Faculdade de Direito, Universidade do Estado do Rio de Janeiro. Rio de Janeiro/RJ, Brasil.

Rodríguez Muñoz, J. M. R. (2004). La alternativa fiscal verde. Valladolid (España): Editorial Lex Nova. Passos, A.B. da M.; Pozetti, V. C. (2012). IPTU VERDE: Extrafiscalidade aplicada a proteção ambiental do cenário urbano brasileiro. Hiléia: Revista do Direito Ambiental da Amazônia. n. 18. Recuperado en 20 agosto, 2016 de: <http://periodicos.uea.edu.br/index.php/Hileia/article/view/151>.

Peralta, C. E., (2015). Tributação Ambiental no Brasil - reflexões para esverdear o sistema tributário brasileiro. Revista de Finanças Públicas, Tributação e Desenvolvimento. v. 3, n. 3. Recuperado en 20 mayo, 2016, de <http://www.e-publicacoes.uerj.br/index.php/rfptd/article/view/15589>. Acesso em: 20 maio 2016

Piacentini, A. L. S., de São Pedro Filho, F., \& de Almeida, F. M. (2015) Estudo epistemológico sobre práticas extrafiscais de gestão urbana sustentável. Revista Cientifica Internacional. n. 1, v. 10, p. 5179, jan./mar. Rio de Janeiro. 
Ramos, J. E. S. (2006) Tributação ambiental: O IPTU e o meio ambiente urbano. IBET.

Ribeiro, M. de F., \& Ferreira, J. S. A. B. (2011). O papel do estado no desenvolvimento econômico sustentável: reflexões sobre a tributação ambiental como instrumento de política pública. Hiléia: Revista do Direito Ambiental da Amazônia, n. 17, p. 136-16 Amazonas.

Rossi, A., Martinez, A. L., \& Nossa, V. (2011). Ecológico sob o enfoque da tributação verde como meio da sustentabilidade econômica e ecológica: experiência do Paraná. Dissertação (Mestrado) Programa de Pós-Graduação em Ciências Contábeis, Fucape, Vitória.

Thalmann, P. (2004). The public acceptance of green taxes: 2 million voters express their opinion. Public Choice, v. 119, n. 1-2, p. 179-217.

Torres, H. T. (2011). Desenvolvimento, meio ambiente e extrafiscalidade no Brasil. Revista Videre, Dourados, MS, ano 3, n. 6, p. 11-52.

Vasco, D. C., \& Herrera, P. M. (2004) Marco General Jurídico de la tributación médio ambiental: concepto, marco constitucional y marco comunitário. In: Buñuel González, M. (Org.). Tributación medioambiental: teoría, práctica y propuestas. Madrid (España): Civitas Ediciones.

Ventosa, P. I. Forn, M. C. Sora, M. J. Sanz, S. S. (2015); Estado actual de la fiscalidad ambiental en España y perspectivas de futuro. In: Martinez, F. A. (Org). Fiscalidad ambiental en España: situación actual y perspectivas de futuro. Pamplona (España): Arazandi. 